Sc Nikola Lekic, potpukovnik, dipl. inż. Vojna akademija - Odsek logistike, Beograd

\section{MERNA METODA ZA ANALIZU RADARSKE POVRŠINE ROTIRAJUĆEG OBJEKTA*}

UDC: $621.396: 969.3: 53.083$

Rezime:

$U$ radu je opisana merna metoda za analizu radarske površine rotirajućeg objekta. Predstavljeni su merni sistem i postupak obrade izmerenih rezultata. Dobijeni rezultat je radarska slika rotirajućeg objekta.

Ključne reči: merenje radarske površine, visokorezoluciona radarska slika.

\title{
RADAR CROS SECTION ANALYSIS OF ROTATING OBJECTS
}

\section{Summary:}

In the paper the radar cross section of rotating objects is analyzed. The measurement systems and data processing are described. The result is a cross range imaging of rotating objects.

Key words: radar cross section measurements, high resolution radar imaging.

\section{Uvod}

Realni radarski ciljevi imaju složeni geometrijski oblik. Sposobnost refleksije elektromagnetskih talasa je osobina karakteristična za svaki radarski cilj, i opisuje se pojmom radarske povrsine $\sigma$. Zavisnost karakteristika refleksije elektromagnetskih talasa od ugaonog zakreta radarskog cilja opisuje se dijagramom refleksije $\sigma(\theta, \phi)$.

Razvoj radarskih senzora i njihova primena u izvidackim sistemima i sistemima sa radarskim samonavodenjem nagla§ava znacaj radarske površine kao važnog parametra u funkciji ,preživljavanja“" potencijalnog cilja. Poznavanje srednje

\footnotetext{
"Rad je saopsten na strucnom skupu TOC KoV, Ispitivanje kvaliteta sredstava NVO", 18. novembra 2003. u Beogradu.
}

vrednosti radarske površine $\sigma$ i dijagrama refleksije $\sigma(\theta, \phi)$ vił̌ nije dovoljno.

Složeni radarski ciljevi, sa stanovista refleksije elektromagnetskih talasa, mogu se razložiti na konačan broj elementarnih reflektora, koji postaju sekundarni izvori zračenja [1]. Mesta maksimalne refleksije elekromagnetskih talasa, nazivaju se bljestave tacke [2]. U slučaju poznavanja njihove pozicije na objektu, u procesu razvoja moguć je promenom oblika konstrukcije, ili promenom konstruktivnog materijala, uticati na njihovu velicinu radi umanjivanja radarske povrsine. Metode analize položaja blještavih tačka cesto se nazivaju metode analize radarske slike.

Kod ovih metoda koriste se memi radarski sistemi, koji u zavisnosti od predaj- 

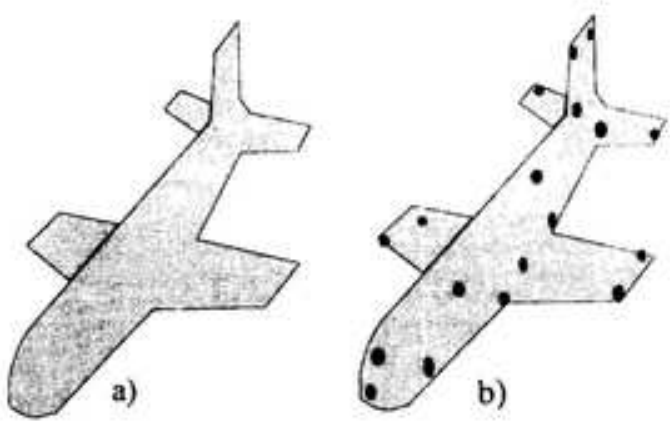

SI. I - a) Radarski cilj, b) Polozaj ,. blještavih taćaka"

nog signala mogu biti: radar sa kontinuiranim zračenjem (CW), frekventno modulisan (FM-CW) radar, CW radar sa upravljivim pomičnim vremenskim vratima $\mathrm{i}$ amplitudno modulisan CW radar [3].

$\mathrm{U}$ ovom radu opisan je merni sistem za analizu radarske slike rotirajućeg objekta, i na odabranim objektima izvršna je eksperimentalna verifikacija metode.

\section{Metoda eksperimentalne analize} radarske slike rotirajućeg objekta

Geometrijske koordinate, koje se vezuju za objekat u odnosu na merni sistem, su daljina $i$ azimut.

Distribucija „bljestavih tačaka“ po azimutu dobija se na osnovu relativnog

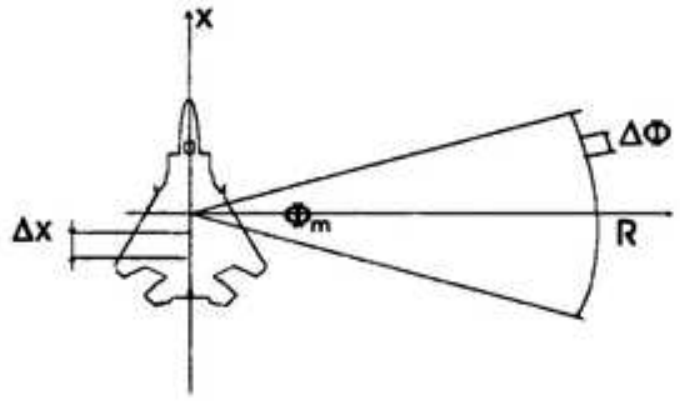

Sl. 2 - Geometrija mernog mesta i dobijanje sintetizovanog otvora kretanja između antene mernog sistema i objekta, bilo da se antena kreće uz nepokretan cilj, ili da je ona nepokretna a cilj rotira u odredenom ugaonom opsegu, slika 2. Odabiranjem signala (amplituda i faza) reflektovanog od objekta u više ugaonih pozicija, formira se sintetizovan otvor. Primljeni signal i distribucija „blještavih tacaka“ objekta povezani su Furijeovom transformacijom. Potrebni ugaoni interval u kome se vrši odabiranje reflektovanog signala, zavisi od željene rezolucije. $\mathrm{Za}$ interval odabiranja $\Delta \Phi<\lambda /(2 \otimes)$, gde je $D$ širina objekta, rezolucija po azimutu iznosi [3]:

$$
\Delta x=\frac{\lambda}{4 \sin \left(\Phi_{m} / 2\right)}
$$

gde je:

$\lambda$ - talasna dužina, $\Phi_{m}$ - ugaoni opseg odabiranja.

Koriscenjem signala frekventnog opsega $B$ i odabiranjem reflektovanog signala $u$ jednakim frekvencijskim intervalima, Furijeovom transformacijom omogućena je distribucija ,blještavih tacaka" po daljini. U tom slucaju rezolucija po daljini iznosi [3]:

$$
\Delta R=\frac{c}{2 B}
$$

gde je:

$\Delta R$ - rezolucija po daljini,

C - brzina svetlosti,

$B$ - sirina frekventnog opsega.

\section{Merni sistem}

U okviru eksperimentalne provere merne metode, realizovan je merni sistem prema slici 3 . 


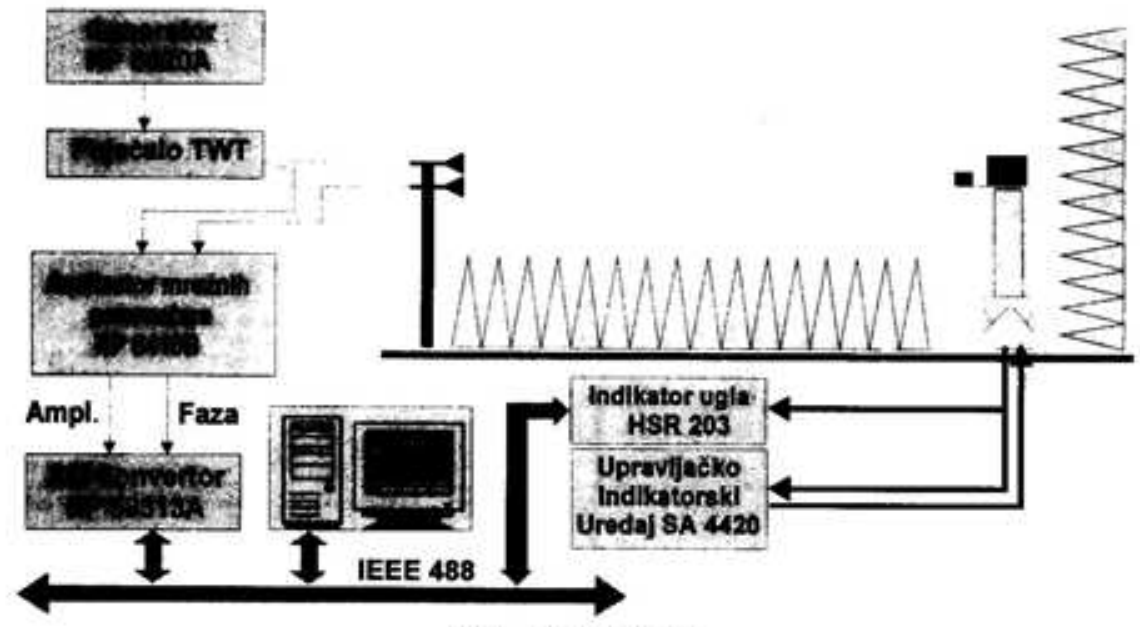

Sl. 3-Merni sistem

Sa generatora HP $8620 \mathrm{~A}$ signal se preko pojačavača Varian TWT VZX $698 \mathrm{~F}$ vodi na predajnu levak antenu. Deo signala se preko usmerenog sprežnika vodi na analizator mrežnih parametara HP $8410 \mathrm{~B}$ sa indikatorom amplitude i faze HP 8413A. Reflektovano polje od cilja prima se prijemnom levak antenom, i vodi na ulaz analizatora mrežnih parametara. Sa indikatora amplitude i faze HP $8413 \mathrm{~A}$ signal amplitude $\mathrm{i}$ faze polja vodi se na A/D konvertor HP 59313A. U merni sistem je uključen računar sa IEEE488 karticom koji na osnovu informacije - uglu sa digitalnog davača ugla DDC HSR 203 upravlja A/D konvertorom HP 59313 A i prikuplja podatke koji se nakon završenog merenja obrađuju.

Upravljanje sa azimut-elevacionim postoljem SA M5301 vrši se pomoću upravljacko-indikatorskog uredaja SA 4620 .

Obrada izmerenih podataka i njihov prikaz realizovana je u programskom paketu MATLAB [4].

\section{Eksperimentalni rezultati}

Pomoću opisanog mernog sistema izvršena je analiza dva radarska cilja: pravougaone ploče stranica $0,223 \mathrm{~m} \times$ $0,23 \mathrm{~m}$, koja je ujedno služila kao etalon, i cilja koji se sastoji od iste pravougaone ploč i dodate male ploðe stranice $0,08 \mathrm{~m}$ na rastojanju od $0,17 \mathrm{~m}$, slika 4 .

Merenje je izvršeno na mernom mestu delimično prekrivenom elektromagnetskim apsorberima. Rastojanje između antena i postolja od stiropora na kome su se nalazili ciljevi, je 5,40 m. Merenje je
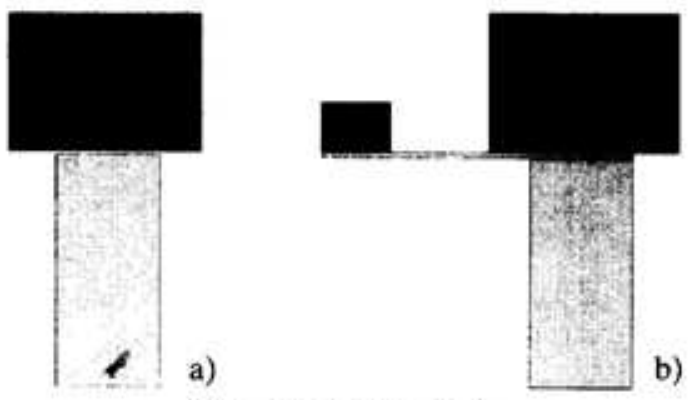

SI. 4-a) cilj 1, b) cilj 2 

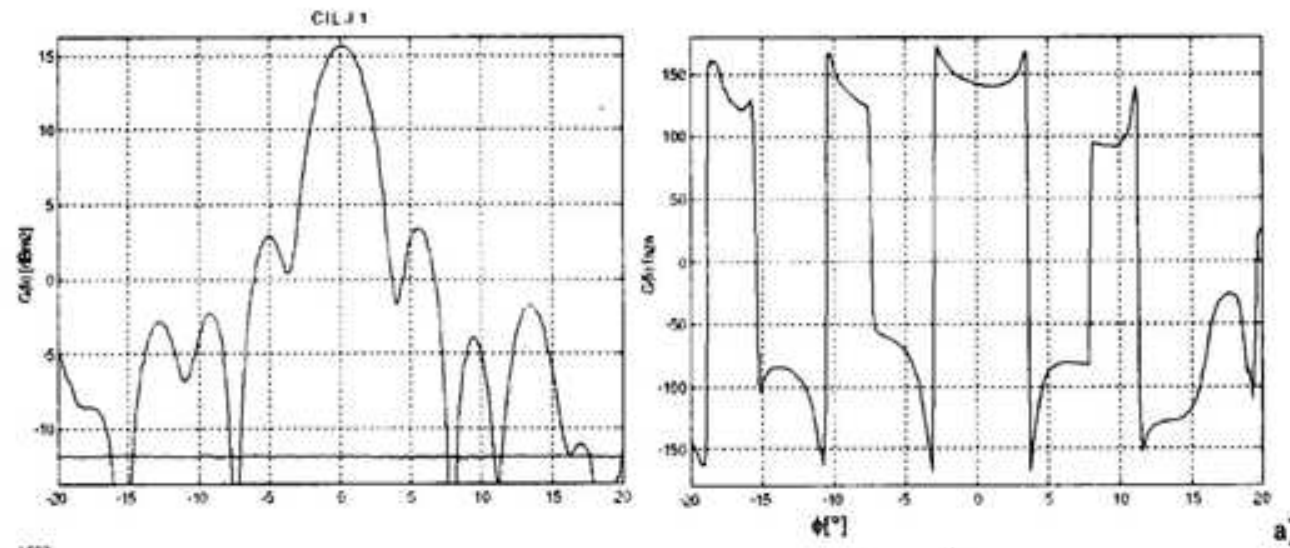

$\left.\phi{ }^{*}\right]$


SI. 5-Dijagram refleksije

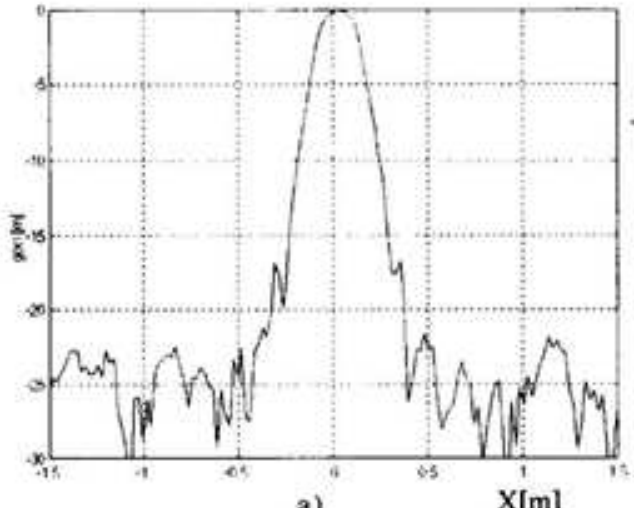

a)

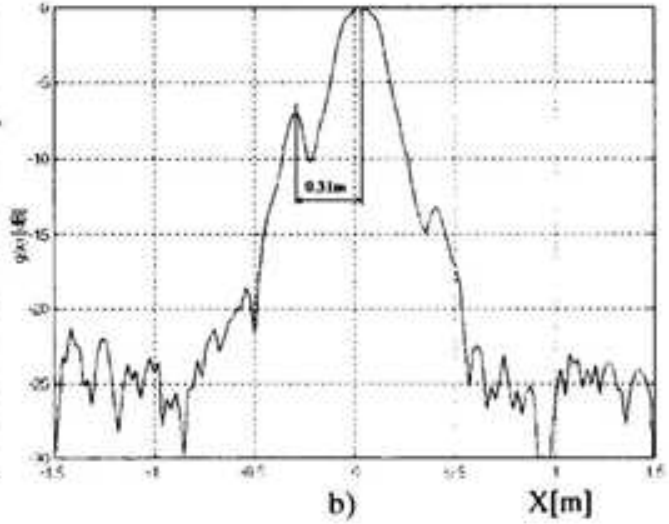

Sl. 6-Distribucija „bljesttavih tačaka": a) cilj 1, b) cilj 2 
izvršeno na frekvenciji $10,049 \mathrm{GHz} u$ ugaonom opsegu od $40^{\circ}$ u 256 tačaka.

Izmereni dijagrami refleksije cilja 1 i 2 prikazani su na slici 5 .

$\mathrm{Na}$ izmerenim podacima uocava se da dodavanje manje ploxice cilju 1 izaziva manje promene u dijagramu refleksije, koje se ogledaju u većem maksimumu cilja 2 za $0,54 \mathrm{~dB}$ u odnosu na cilj 1 . Postavljanje male ploce dovelo je do povecanja nivoa desnog boka dijagrama refleksije za 1,9 dB. Promene se ogledaju i kod faznog dijagrama u centralnom delu, ali uz očuvanje tačaka promene predznaka faze.

Izvršena je obrada izmerenih poda-

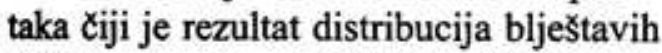
tacaka po osi $\mathrm{x}$, prikazan na slici 6 . Distribucija bljestavih tačka prati fizicke dimenzije ciljeva, tako da se za cilj 1 moze proceniti da na nivou od $-3 \mathrm{~dB}$ njegova Sirina iznosi $0,25 \mathrm{~m}$. Greška u dimenzijama, za oko pola talasne dužine sa obe strane, posledica je efekta ivice ploce.

$\mathrm{Na}$ distribuciji bljestavih tačaka cilja 2 uocava se dodata pločica kao veoma izražen bok sa leve strane. Razmak između položaja maksimuma iznosi $0,31 \mathrm{~m}$ sto se slaže sa fizickim dimenzijama razmaka između centra velike i male ploce.

Slicnim mernim sistemom, gde se koristi generator HP 4420 i kao A/D konvertor digitalni analizator signala HP 5420 izvršena je dvodimenzionalna analiza modela aviona od aluminijuma, dužine $0,90 \mathrm{~m}$ i širine $0,60 \mathrm{~m}$, slika 7 . Merenje je izvedeno u kontrolisanim uslovima $\mathrm{u}$ antieho komori. Objekat, model aviona, nalazio se na postolju od stiropora na visini $1,54 \mathrm{~m}$, bočno postavljen na udaljenosti od $6,30 \mathrm{~m}$ od predajne $\mathrm{i}$ pri- jemne levak antene postavljene na visini od $1,80 \mathrm{~m}$.

Cilj je rotirao po uglu u opsegu $\pm 7^{\circ}$, diskretno pomeran u 128 tacaka. Za svaki ugaoni položaj vršeno je merenje dijagrama refleksije, uz diskretnu linearnu promenu frekvencije predajnog signala u 128 tačaka pri cemu je ostvaren frekventni opseg $2,5 \mathrm{GHz}$ (pocetna frekvencija $f_{I}=8,5 \mathrm{GHz}$, krajnja frekvencija $f_{2}=11 \mathrm{GHz}$ ). Dobijeni dijagram refleksije prikazan je na slici 8 .

Izmereni podaci amplitude i faze primljenog signala pretvoreni su u dvodimenzionalno kompleksno polje. Nakon izvršene FFT, dobijena je distribucija „bljestavih tacaka“ površine komore i modela aviona prostorno raspoređenih po

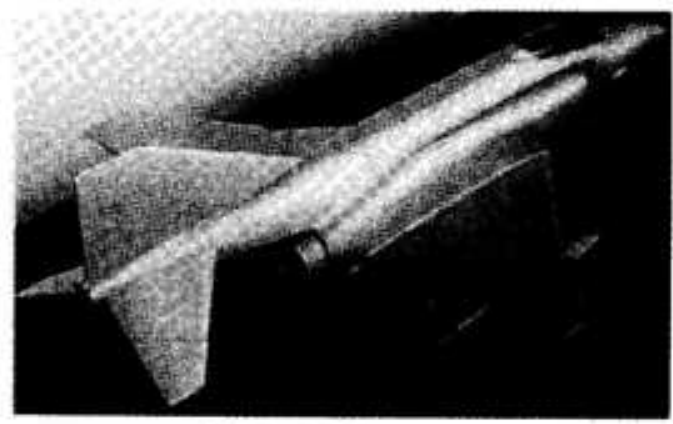

St. 7-Model aviona

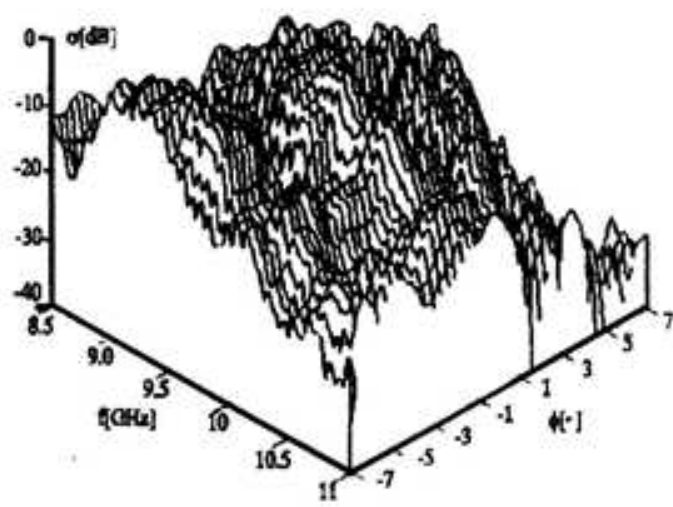

Sl. 8-Izmereni dijagram raspršenja modela aviona (normalizovana amplituda) 


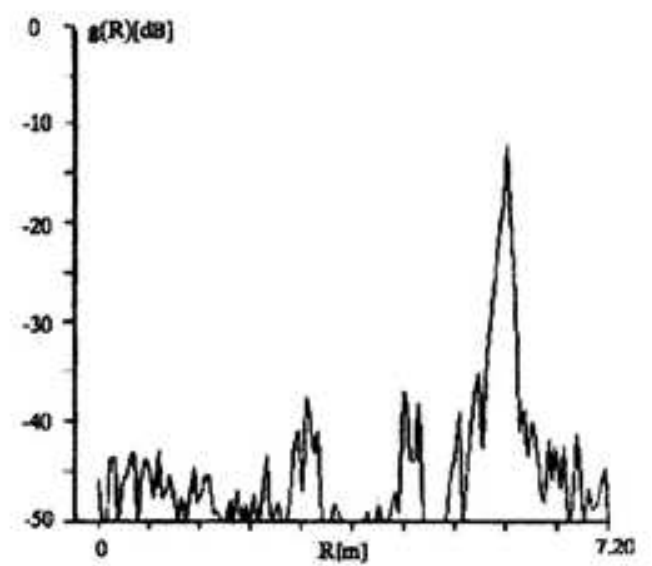

SI. 9-Normalizovana radarska slika modela aviona $128 \times 128$ tacaka

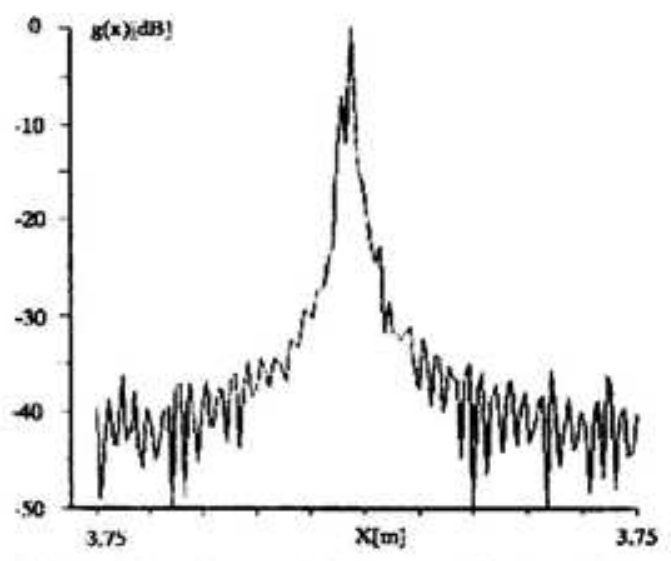

Sl. 10-Distribucija ..blještavih tačaka " po daljini dobijena iz preseka normalizovane radarske slike

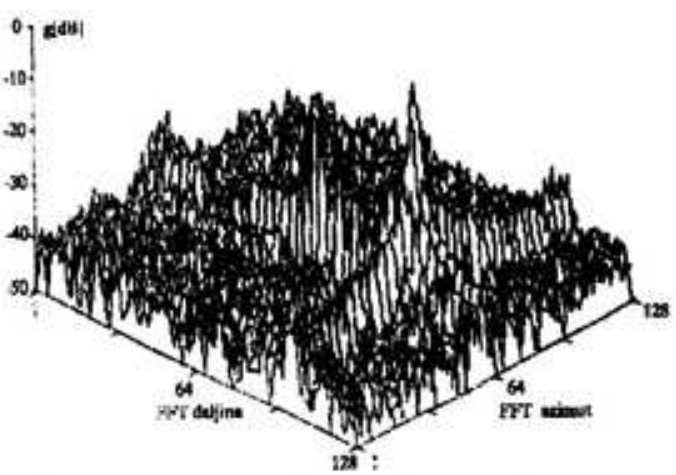

Sl. II - Distribucija „,bljestavih tačaka " po azimutu dobijena iz normalizovane radarske slike azimutu i daljini, koja je normalizovana po intenzitetu i prikazana na slici $9 . \mathrm{Na}$ osnovu uslova merenja potencijalna rezolucija po daljini je $\Delta R=0,06 \mathrm{~m}$, a po azimutu od $\Delta x_{1}=0,056 \mathrm{~m}$ za frekvenciju $11 \mathrm{GHz}$ do $\Delta x_{2}=0,072 \mathrm{~m}$ za frekvenciju $8,5 \mathrm{GHz}$. U tom slữaju prostor podataka odgovara po daljini $7,20 \mathrm{~m}$, a po azimutu od 7,16 m do $9,21 \mathrm{~m}$.

Na slici 10 prikazan je presek radarske slike po daljini. Sa slike se može odrediti položaj modela, koji prema maksimumu iznosa „blještavih tačaka“ odgovara daljini od 6,12 m, uz sirinu od $0,66 \mathrm{~m}$.

Na slici 11 prikazan je presek radarske slike po azimutu. Sa slike se vidi da je položaj modela u centru, dok je procenjena dimenzija na osnovu ,bljestavih tacaka" oko $0,90 \mathrm{~m}$.

\section{Zaključak}

U radu je opisana metoda eksperimentalne analize radarske slike rotirajućeg objekta.

Opisanim mernim sistemom moguce je izvrsiti jednodimenzionalnu analizu „bljestavih tacaka“" po poprečnom preseku ( $\mathrm{x}$ osi). Merenjem dijagrama refleksije u odredenom frekventnom opsegu (primena generatora sa automatskom promenom frekvencije), moguce je izvršiti dvodimenzionalnu analizu blještavih tačaka po poprěnom preseku ( $x$ osi) i po daljini.

Iz dobijenih rezultata može se zaključiti da distribucija „,blještavih tacaka“ odgovara fizickim dimenzijama analiziranih objekata.

Ovako dobijeni podaci o radarskoj slici nekog objekta mogu se iskoristiti kao polazna osnova za modelovanja i si- 
mulaciju radarske karakteristike cilja radi analize odziva radarskih senzora.

$\mathrm{Na}$ osnovu analize ,bljestavih tačaka" moguće je izračunati fazni centar i radarsku površinu objekta, simulirati doprinos svakog rasprsivača i na osnovu toga preduzimati konkretne aktivnosti radi smanjenja radarske vidljivosti sredstva.
[1] Zatkalik, A.: Radiolokacija I deo, Nauka, Beograd, 1995.

[2] Razingar, A.: Elektronsko izviđanje i maskiranje, VINC, Beograd, 1989.

[3] Mensa, D. L.: High Resolution Radar Imaging, Artech House, Dedham, MA, 1984.

[4] Signal Procesing Toolbox User's Guide, The Math Works, Inc., Natick, MA, 1992. 